\title{
Understanding contextual influences of community reintegration among injured servicemembers
}

\author{
Brent L. Hawkins, PhD, LRT/CTRS; ${ }^{*}$ Francis A. McGuire, PhD; Sandra M. Linder, PhD; Thomas W. Britt, PhD \\ Clemson University, Clemson, SC
}

\begin{abstract}
As part of a larger mixed-methods research project investigating the influence of contextual factors on community reintegration $(\mathrm{CR})$, this qualitative study sought to understand the subjective experiences of injured servicemembers and their perception of how contextual factors influenced their CR. More specifically, this article addresses how the influences of contextual factors differ between injured servicemembers with different levels of CR. Using a phenomenological framework, semistructured interviews were conducted with nine injured, community-dwelling servicemembers with low, moderate, and high levels of CR (three per category). Participants provided in-depth descriptions of the contextual barriers and facilitators of CR. Thematic analysis indicated the importance of social support and personal factors (e.g., self-efficacy, personal motivation) as the primary means for being reintegrated into their homes and communities. Other themes indicated factors that had an indirect but important influence on CR, including adapted sports, recreation, and other social programs; rehabilitation programs and therapists; school, work, and volunteering; and organizations and policies in developing social supports and personal factors. Comparisons between servicemembers indicated that participants with low $\mathrm{CR}$ described many more contextual barriers and far fewer contextual facilitators to reintegration than those with high CR. Those with moderate CR were unique in that they described many facilitators and barriers to reintegration.
\end{abstract}

Key words: community-dwelling, community reintegration, contextual factors, environmental factors, general self-efficacy, injured military servicemembers, personal factors, phenomenology, rehabilitation, social support.

\section{INTRODUCTION}

Community reintegration (CR) refers to returning to participation in home, social, and community living after deployment and, in many cases, after injury and discharge from rehabilitation [1-2]. Researchers have investigated CR among injured servicemembers from the Global War on Terrorism and indicated that many experience difficulty with CR after injury [3-6]. Authors have conceptualized and measured CR with injured servicemembers, but relatively little is known about the personal and environmental factors (i.e., contextual factors) that influence the injured servicemembers' ability to reintegrate with their homes and communities. Yet, researchers agree that the potential effects of contextual factors, as conceptualized by the International Classification of Functioning, Disability and Health (ICF), likely have a significant effect on CR [7-11].

\footnotetext{
Abbreviations: $\mathrm{CR}=$ community reintegration; $\mathrm{EOP}=$ Extent of Participation; ICF = International Classification of Functioning, Disability and Health; PTSD = posttraumatic stress disorder; SCI $=$ spinal cord injury; $\mathrm{SCT}=$ Social Cognitive Theory; SWP = Satisfaction with Participation; VA = Department of Veterans Affairs.

*Address all correspondence to Brent L. Hawkins, PhD, LRT/CTRS; Department of Parks, Recreation \& Tourism Management, Clemson University, 128 McGinty Ct, 263 Lehotsky Hall, Clemson, SC 29634; 864-656-0458; fax: 864-656-2226. Email: blhawki@clemson.edu
}

http://dx.doi.org/10.1682/JRRD.2014.08.0196 
Contextual factors are the "physical, social, and attitudinal environment in which people live and conduct their lives" [12]. Previous research studying the influence of contextual factors on individuals with disabilities report the significant effect of these factors on ability to participate in life activities and life satisfaction among civilians with spinal cord injury (SCI) [8] as well as CR among civilians with SCI [9]. Other studies with military servicemembers suggest the importance of contextual factors in many aspects of military and postmilitary life, such as the importance of social support in suicide prevention [13], preference of family-based mental health services [14], and social comparison with other servicemembers to increase participation in recreation and sport [15-16].

A recent call has been made to conduct more "veteran-centric" research that incorporates the subjective experience of $\mathrm{CR}$ among injured servicemembers to gather a greater understanding of the contexts that shape CR [1]. Qualitative methods infused as part of a mixedmethods approach can assist with identifying the factors that influence CR, as well as explaining their influence. As an example of qualitative designs as part of a mixed method framework in this line of research, Resnik and Allen conducted a qualitative study within an instrument development mixed-methods approach [4]. The authors used specific components of the ICF's nine Activities and Participation domains as a framework for analysis of interview data with injured servicemembers. Researchers found that most injured servicemembers in the sample reported problems in at least one or more areas of CR (e.g., learning and applying knowledge; general tasks and demands; communication; mobility; self-care; major life areas; domestic life; interpersonal interactions; community, social, and civic life). The authors concluded that injured servicemembers are at a high risk of poor reintegration given the prevalence of brain injury and posttraumatic stress disorder (PTSD). In a more recent study, Wands conducted interviews as part of a concurrent mixed-methods approach with student servicemembers in regards to their experience with transitioning back to home and school after combat deployment [17]. This study describes the struggle that the sample of servicemembers experienced with returning while also describing the approaches they employed to negotiate their challenges transitioning to civilian life. These studies were able to incorporate qualitative methods to give voice to their participants and address their research questions in a comprehensive manner.

Therefore, this qualitative study, as the follow-up phase of a larger mixed-methods explanatory sequential research study [18], aimed to capture the subjective experience of community-dwelling, injured servicemembers to better understand how contextual factors influence CR.

This study is framed within the ICF and Social Cognitive Theory (SCT) frameworks. The ICF identifies and classifies the various domains of health that influence functioning, including the personal and environmental factors (e.g., contextual factors) that act as barriers to or facilitators of functioning. The concept of CR can be captured within the ICF's Activities and Participation domains (e.g., a task or action and a person's ability to execute that task or action in a life situation) [12], as demonstrated in Resnik and Allen's study [4]. SCT is a theoretical framework that explains motivation by placing a person's behavior in the context of social and personal environments. Although the ICF includes personal factors in its conceptualization, it does not fully classify the components. In contrast, SCT operationalizes personal factors into more comprehensive components, including self-efficacy, behavioral capacity, and selfregulation [19]. Using these frameworks together assisted with classifying and understanding how internal personal forces and external environments (e.g., contextual factors) affected injured servicemembers and their CR.

\section{METHODS}

This study presents the second phase of a larger explanatory sequential mixed-methods study that sought to understand the influence of contextual factors on CR among injured, community-dwelling servicemembers. The quantitative phase of this larger study identified the contextual factors that influence CR [20]. The qualitative phase, presented in this article, contributed to the mixedmethods study by serving three purposes: (1) to understand the subjective experiences of injured servicemembers and their perception of how contextual factors influenced their CR, (2) to explain how contextual factors influence CR of injured servicemembers with different levels of CR, and (3) to better address the contextual facilitators of CR in addition to contextual barriers. Phenomenology, the study of individuals' lived experiences through the sharing of personal reflections on a certain 
experience [21], guided this phase of research. Semistructured interviews were conducted with each participant to obtain a rich description that documents his or her personal experiences with CR after injury and/or rehabilitation. These experiences were analyzed to determine an overall understanding of CR for injured servicemembers.

\section{Participants and Procedures}

Participants included nine servicemembers who served in the Global War on Terrorism, had single or multiple physical and/or psychological/emotional injuries, and were community-dwelling. Recruiting servicemembers who lived in their homes and communities was important to the purpose of the study because their experiences with $\mathrm{CR}$ allowed them to reflect and provide insight into the factors influencing their CR. To obtain a sample of community-dwelling servicemembers, recruitment consisted of contacting (1) adaptive sport clinics, camps, and other recreational programs; (2) online support forums and services; (3) transitional programs between rehabilitation and community re-entry; (4) advocacy groups for veterans benefits; and (5) professional organization listservs. These programs and individuals shared the study's information with the servicemembers through email, printed and digital flyers, or word of mouth. Participants for this qualitative phase were selected using a stratified purposeful sampling technique drawing from the initial and larger sample identified in the quantitative phase of the mixed-methods study [20]. Stratified purposive sampling is common among mixedmethods research and includes dividing the sample into homogeneous strata (i.e., clusters) based on one or more characteristics, then purposively selecting participants from each strata [22].

As part of the survey in the quantitative phase, clusters were based on participant scores on the Extent of Participation (EOP) and Satisfaction with Participation (SWP) subscales of the CR of Injured Servicemembers measure [6]. Visual inspection of a scatter plot of EOP and SWP scores indicated the potential of three clusters of participants. Results of a K-means cluster analysis further supported three clusters representing low scores on $\mathrm{CR}$, moderate scores on $\mathrm{CR}$, and high scores on CR consisting of 10, 22, and 18 participants, respectively (Figure 1) [20]. Cutoff scores have not been established for the EOP and SWP subscales; therefore, the clusters were based on the cluster analysis findings. Proximity to cluster centers determined cluster identification. Cluster cen-

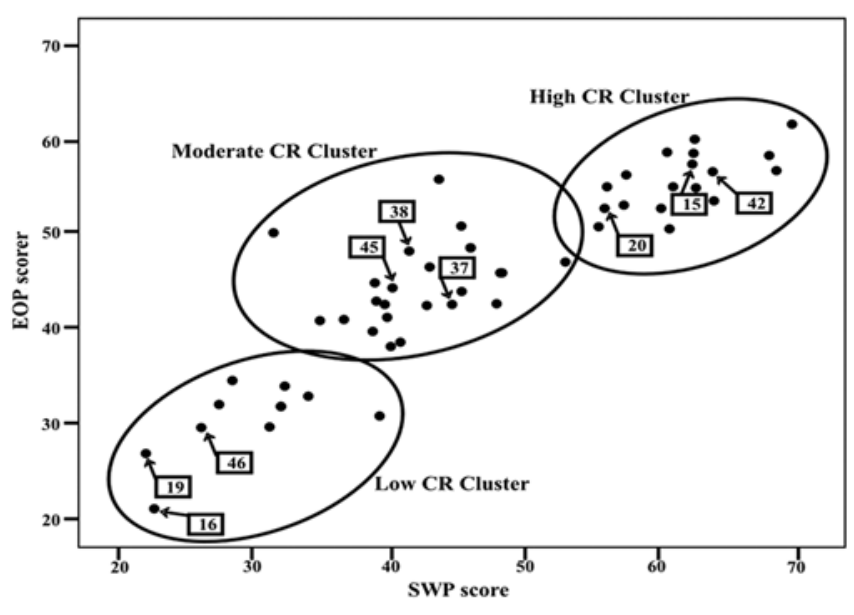

Figure 1.

Interview participants and cluster affiliation. Case numbers indicate servicemembers who participated in interview. $\mathrm{CR}=$ community reintegration, $\mathrm{EOP}=$ Extent of Participation, SWP = Satisfaction with Participation.

ter scores were 21.21 on EOP and 22.61 on SWP for the low CR group, 48.36 on EOP and 41.55 on SWP for the moderate CR group, and 61.70 on EOP and 69.77 on SWP for the high CR group.

Participants were considered for interviews if they indicated their agreement to participate in the follow-up interview and provided their name and contact information at the end of the survey. Researchers selected participants who exhibited the most variation from participants in other clusters and responded to the researchers' followup interview requests. Selecting participants according to their cluster affiliation contributed to a better understanding of why differences in CR scores and experiences existed. More specifically, participants who had high scores in the high CR cluster, moderate scores in the moderate CR cluster, and low scores in the low CR cluster had priority in the selection process. This process generated nine participants who completed an interview. Participants were interviewed by telephone and audio recorded. Face-to-face interviews were not used because of the diverse geographic locations of the participants in relation to the interviewer. Some researchers support that telephone and face-to-face interviews can yield comparable information [23]. Given the comprehensive responses and length of the telephone interviews in this study, the interview methods employed in this study were successful. 
During the interviews, participants were asked questions that prompted them to reflect on their experiences and share how they perceived various environmental and personal factors that assisted and hindered their ability to participate in home and community activities. As necessary, probing questions were asked to obtain or clarify additional information on the comments and ideas of the participant. Additional probing questions were also asked and focused on specific environmental and personal factors (e.g., attitudes of others, natural and human-made environments, products and technology, services or programs, personal motivation, personal goal setting) if the primary questions were not well understood or if clarification was needed. Categories of the primary interview questions included (1) general CR experience (e.g., Have you been able to reintegrate back into your home and community like you thought you would be able to? Why or why not?), (2) facilitators of CR (e.g., What types of things have supported your reintegration?), (3) barriers to reintegration (e.g., Is there anything in particular that has hindered you from reintegrating into your home and community?), and (4) closing questions (e.g., Do you have any suggestions for ways rehabilitation programs and other programs can better prepare injured servicemembers with reintegrating?).

\section{Qualitative Analysis}

Telephone interviews were recorded using a digital voice recorder and transcribed into electronic text files. Next, the in-depth data were methodologically reduced to identify potential meanings in participant statements $[21,24]$. In phenomenological fashion, analysis consisted of repetitive reading through transcripts line-by-line to find significant, nonoverlapping statements that captured the essence of the participant's meaning in regards to a question or topic of thought. These statements, called meaning units, were identified through a peer review and examination process [24]. This process was used to derive potential meanings from participant statements and enhance the consistency and dependability of the results [21,24-25]. An additional reviewer read through all transcripts and developed meaning units and themes independently from the initial researcher. Once meaning units were identified for each participant, an iterative clustering process occurred where the units were grouped into thematic categories. The clustered meaning units were elaborated into textual descriptions to explain the essence of the participants' CR experiences, both individually and within the clusters $[21,26]$. Concepts of facilita- tors and barriers to CR were intentionally sought during analysis; however, the researcher also allowed additional themes to develop naturally as a result of the participant/ researcher dialog and to maintain an inductive approach to analysis. The reviewer was informed of the research questions for the study and was requested to find common facilitators and barriers to CR. However, the reviewer was also encouraged to develop additional themes as supported in the narratives. After independent analysis was completed, the researcher and reviewer discussed their individual interpretation of the narratives and resulting themes. Comparison of meaning units and themes yielded comparable results, and any alternate interpretation of the data was carefully deliberated until 100 percent agreement was reached. The purpose of adding another reviewer was not necessarily to ensure complete consensus between researchers but rather to confirm that the results make sense given the complexity of the data and to aid in trustworthiness [27].

The data were analyzed for the qualitative sample as a whole, as well as within clusters (low, medium, high CR). Comparison of personal narratives across clusters was necessary to develop overarching themes related to barriers and facilitators of CR. Between-cluster comparisons were necessary to further develop an explanation of cluster differences based on common themes regarding participants' experiences with CR.

Member checking was also implemented to aid in the validation of the participant's responses and the developed themes to clarify potential misunderstandings and enhance credibility of the researcher's interpretation of participants' intended meanings [25,28-29]. All interview participants were provided an email summary of the overarching themes and were asked to review and verify whether these themes correctly summarized and captured their statements. A verification table resulting from the member-checking procedures is available upon request. The study received approval through Clemson University's Institutional Review Board prior to implementation.

\section{RESULTS}

Of the 31 servicemembers who indicated their interest in being contacted for an interview in the initial survey, 9 followed through with the interview. Three interviews from each cluster were conducted to gain indepth descriptions from servicemembers representing 
each level of CR. Figure 1 illustrates the interview participants, case numbers, and CR cluster affiliations. Information on interview participants with representative case numbers are in the Table. The duration of interviews ranged from 33 to $61 \mathrm{~min}$, with an average of $48 \mathrm{~min}$. Seven participants responded to the email for the member-checking procedure, and all seven verified the themes were accurate of their experiences, including the theme's role as a facilitator and/or barrier in their CR process, suggesting no change to the thematic structure. Pseudonyms replaced participant names to ensure confidentiality.

\section{Thematic Findings}

Qualitative analysis yielded six themes reflecting participant experiences with CR. Exemplary descriptions of participant responses are included to provide a textural description and provide evidence of the themes that describe how the influence of contextual factors affect CR. Overarching themes across clusters are described first, followed by summary explanations of how each cluster differed in their descriptions of the contextual factors that influenced their CR. Figure 2 graphically represents the structure of the themes.

Across all clusters, thematic analysis reflected the direct influence of (1) social support and (2) personal factors (e.g., self-efficacy, motivation) on the servicemembers' ability to reintegrate. Analysis also indicated the indirect but critical influence of (3) adaptive sport, recreation, and other social programs; (4) rehabilitation programs and therapists; (5) school, work, and volunteering; and (6) organizations and policies in their ability to influence the

Table.

Interview participant information.

\begin{tabular}{|c|c|c|c|c|c|c|c|}
\hline Case & $\begin{array}{l}\text { Participant } \\
\text { Pseudonym } \\
\text { (cluster) }\end{array}$ & Sex & $\begin{array}{l}\text { Age } \\
(\mathrm{yr})\end{array}$ & Injuries & $\begin{array}{l}\text { Time Since } \\
\text { Injury } \\
\text { (yr) }\end{array}$ & Conflict & How Injured \\
\hline$\overline{16}$ & $\begin{array}{l}\text { Jacob } \\
\text { (low CR) }\end{array}$ & Male & 37 & $\begin{array}{l}\text { Bulging discs lower back/neck, } \\
\text { head trauma, other orthopedic, } \\
\text { PTSD, depression }\end{array}$ & 10 & OIF, OEF & $\begin{array}{l}\text { Improvised } \\
\text { explosive device }\end{array}$ \\
\hline 19 & $\begin{array}{l}\text { Anthony } \\
\text { (low CR) }\end{array}$ & Male & 33 & $\begin{array}{l}\mathrm{C} 2 \text { and } \mathrm{C} 7 \mathrm{SCI} \text {, severe } \mathrm{BI} \text {, blind in } \\
\text { right eye, GAD }\end{array}$ & 3 & OEF, OND & "In line of duty" \\
\hline 46 & $\begin{array}{l}\text { Sarah } \\
\text { (low CR) }\end{array}$ & Female & 38 & $\begin{array}{l}\text { Vertebral injury with bulging discs, BI, } \\
\text { hearing difficulty, PTSD, depression }\end{array}$ & 2 & OIF, OEF & $\begin{array}{l}\text { Injured during } \\
\text { flight mission }\end{array}$ \\
\hline 45 & $\begin{array}{l}\text { Kathy } \\
\text { (moderate CR) }\end{array}$ & Female & 49 & $\begin{array}{l}\text { Hearing difficulty, PTSD, depression, } \\
\text { GAD, breast cancer, chronic fatigue }\end{array}$ & $\sim 2$ & $\begin{array}{l}\text { OIF, OEF, } \\
\text { OND, } \\
\text { Desert Storm }\end{array}$ & $\begin{array}{l}\text { Experiences } \\
\text { during military } \\
\text { deployments }\end{array}$ \\
\hline 38 & $\begin{array}{l}\text { Jack } \\
\text { (moderate CR) }\end{array}$ & Male & 42 & $\begin{array}{l}\text { Right above-knee amputation, radial } \\
\text { nerve damage in left arm, PTSD, } \\
\text { depression }\end{array}$ & 8 & $\begin{array}{l}\text { OIF, OEF, } \\
\text { OND }\end{array}$ & Gunshot wound \\
\hline 37 & $\begin{array}{l}\text { Ryan } \\
\text { (moderate CR) }\end{array}$ & Male & 37 & $\begin{array}{l}\text { Mild BI, right above-knee amputation, } \\
\text { hearing loss in right ear, PTSD, } \\
\text { depression }\end{array}$ & 9 & OIF & $\begin{array}{l}\text { Rocket-propelled } \\
\text { grenade }\end{array}$ \\
\hline 20 & $\begin{array}{l}\text { Samuel } \\
\text { (high CR) }\end{array}$ & Male & 42 & $\begin{array}{l}\text { BI with seizure disorder, systemic } \\
\text { nerve damage, reflex sympathetic } \\
\text { dystrophy in upper body, hearing } \\
\text { impairment, PTSD }\end{array}$ & 11 & OIF & $\begin{array}{l}\text { Airplane was shot } \\
\text { down }\end{array}$ \\
\hline 15 & $\begin{array}{l}\text { David } \\
\text { (high CR) }\end{array}$ & Male & 38 & $\begin{array}{l}\text { Spinal injury-paraplegia, multiple } \\
\text { fractures, PTSD }\end{array}$ & 5 & OIF, OEF & $\begin{array}{l}\text { Nonmilitary motor- } \\
\text { cycle crash, PTSD } \\
\text { related to military } \\
\text { experiences }\end{array}$ \\
\hline 42 & $\begin{array}{l}\text { Nick } \\
\text { (high CR) }\end{array}$ & Male & 38 & Left below-elbow amputation & 9 & $\begin{array}{l}\text { OIF, Joint } \\
\text { Endeavor }\end{array}$ & $\begin{array}{l}\text { Rocket-propelled } \\
\text { grenade }\end{array}$ \\
\hline
\end{tabular}


Indirect Influences

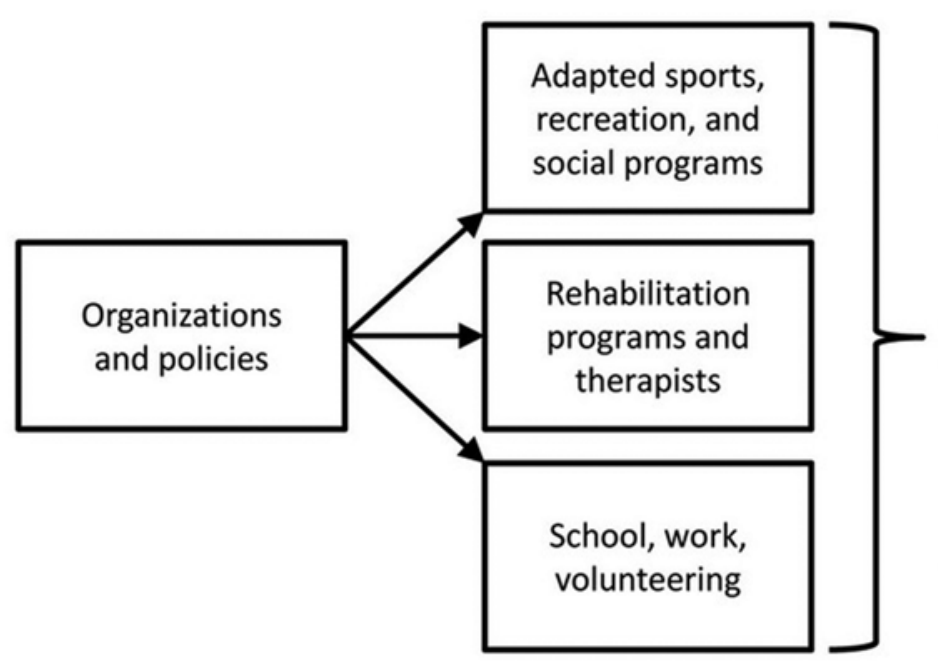

Direct Influences

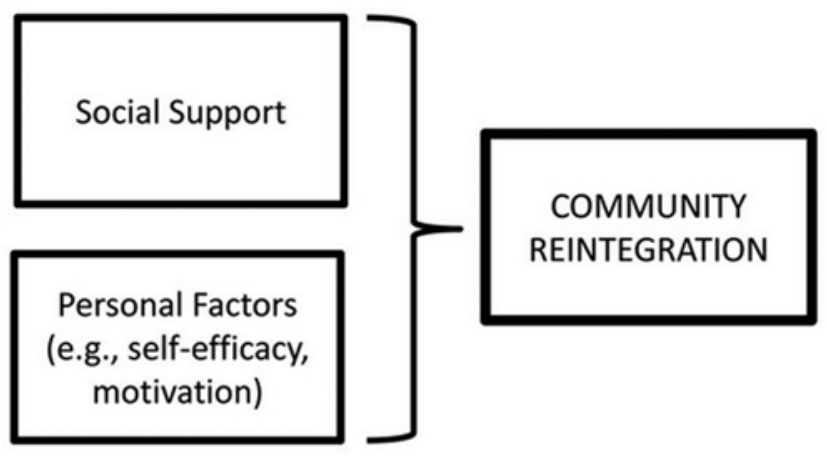

Figure 2.

Thematic structure of contextual factors related to community reintegration.

development of social support and personal factors that, in turn, influenced their CR. Organizations and policies influenced the availability and accessibility of programs, services, and resources; therefore, this theme precedes the other themes in Figure 2.

\section{Social Support (Direct Influence)}

Social support and connections with others were highly influential as both facilitators and barriers of CR. Social support was described in terms of individuals whom participants can depend on during stressful periods, in times of need, and to provide support and encouragement to participate in life activities. The most influential social relationships took the form of family and friend support and connections with other injured and noninjured servicemembers.

Social support as facilitator. Regarding social support as a facilitator, participants discussed the importance of support from family and friends. Wives, in particular, played a major role in helping injured servicemembers with a variety of home and community activities including personal care, home activities, participation in sports, volunteer activities, and other social activities. No participants had husbands; therefore, husbands were not mentioned. Children also influenced participation in social and community activities. Children motivated the partici- pants to be active in the community and to be positive role models. Friends also served a supportive role by being available when needed for simple tasks such as talking on the telephone, keeping the dog during trips, and providing motivation to be active.

My wife certainly respects and sees the value in volunteering and stuff too. She does a lot of volunteering and she supports me in understanding that I need to give up time to do this stuff sometimes, you know. My family is very supportive. You know if there's charity walks, they participate as well. (Ryan [moderate CR cluster])

I have a kid too so that's been a huge portion of my life. ... You just have to be social to get the boy out, so we can meet other people and it kinda forces you to go to birthday parties. All those extra things that children need to do to, you know, for fulfillment. So I've had the opportunity to go to those types of things and it gets me out. (Jack [moderate CR cluster])

Establishing connections with other servicemembers, both injured and noninjured, was very influential in feeling supported and integrated at homes and in the community. Creating connections with other servicemembers allowed participants to regain a sense of camaraderie and 
re-establish the sense of personal identity as part of the military family. Support from other servicemembers also facilitated one participant's decision to report his own mental health difficulties and to continue with treatment.

I started running into my fellow veterans that had been through the same thing or worse. ... I go to all these events and these guys are going strong and they are inspiring to me. So, you know, having the fellow vets around me is a huge support. (Samuel [high CR cluster])

Social support as barrier. While it was clear that social support was a facilitator of CR, it was also evident that certain social support, or lack thereof, served as a barrier to CR. Many participants discussed having inadequate social support in their lives. In some instances, social supporters were no longer accessible because of various living environments and locations.

I guess it's because I don't have (social support), like at home I had my support network, I had my friends, I had my family, I had my mom, my best friend could come over to my apartment and say, "Get your ass up, we're going to go watch a movie." Whereas here, I don't really have that. . . . I have a roommate right now. . . . She is kinda like a negative support for me, like if I don't want to go work out or I don't feel like physically get up and do something, I get called things like a "quitter" ... which has greatly affected me. (Sarah [low CR cluster])

In combination with the effects of their injuries, attitudes in the form of misconceptions and stigma from civilians and other servicemembers also made CR difficult. Negative attitudes toward the participants or making assumptions about their injuries, particularly emotional and psychological injuries, were the most prevalent.

When you get (around) civilians, they have no idea of the injury or how bad you're injured. . . . When I get back they look at me and say, "Well I don't see any missing limbs or anything like that," and you have to explain, "Well you know, I've got six or more concussions, I've got $30 \%$ (Department of Veterans Affairs [VA] disability rating) for TBI. . . . It's hard to explain your injuries to people when they don't understand the concept of it. . . Most of the time I just hide out in my house. I really don't get out too much in public. ... . It's the PTSD. I don't feel comfortable in public anymore. (Jacob [low CR cluster])

\section{Personal Factors (Direct Influence)}

The next primary theme that had a large influence on CR was personal factors. Although the ICF and SCT frameworks did not serve as an a priori analytical template, the term "personal factors" was borrowed from these frameworks and deemed appropriate as a cumulative term referring to the participant's self-efficacy, efforts to overcome barriers, personal motivation to reintegrate, and goal setting as part of self-regulation (e.g., an individual's ability to control and manage his or her behavior).

Many statements related to personal factors were embedded within participant narratives of contextual influences, while other statements related to personal factors were made in response to questions asking how a participant's personal outlook affected his or her ability to reintegrate. Personal factors were critical to the actions taken to reintegrate into homes and communities.

Personal factors as facilitators. As a facilitator of $\mathrm{CR}$, many participants described statements about themselves that reflected their self-efficacy and their personal belief that they had the skills, abilities, and supports necessary to overcome challenges. Some participants explained that these beliefs were a personal trait that had been a part of them for the majority of their lives, but some explained that their personal beliefs were strengthened through their experiences in the military and since their injury. Participants who described aspects of high self-efficacy, were motivated to reintegrate, and exhibited the ability to self-regulate through goal setting were more successful at CR, as determined by their CR scores and their narratives. Their own personal outlooks seemed to play a large role in their CR.

There's nothing that helps you integrate. You have to find your own way. . . . They talk about all these benefits and all these organizations and all the resources that are out there, but it's up to us to go use them.... I just found out about them and made myself do it. (Kathy [moderate CR cluster])

Some participants described various barriers that made it difficult for $\mathrm{CR}$, but they also described their strengths for working around and negotiating barriers. For example, Samuel discussed his efforts to negotiate accessibility barriers in his home:

I wouldn't say anything held me back. I'm just not that kind of guy. If something is not working, just approach it from a different direction.... We 
have been working on it (making his house wheelchair accessible) ourselves a bit at a time over the years, so I have slowly been improving my situation myself. I'm not just going to sit here and wait for someone else to do it. (Samuel [high CR cluster])

Motivation to reintegrate and become involved in home and community activities was also key to CR. For example, motivation to seek and maintain employment when it was not a financial necessity was a response that represented motivation to be productive.

I mean I could have sat around, you know, collecting the VA benefits and hang out while my wife works and we would have been just fine, but I didn't really feel comfortable doing that. So that's something that you know my desire to be productive has been helpful. ... So, for example, I mentioned that I've done that Army 10 miler a few times and that was a main reason for it, was just to go out and say, here I am. (Nick [high CR cluster])

Many responses related to facilitators of CR reflected goal-setting and self-regulation. This occurred most notably among participants in the moderate and high CR clusters. Self-regulation through setting specific, attainable goals and making efforts to achieve those goals seemed to facilitate CR. Goals typically revolved around going back to school, excelling at a job, Paralympic aspirations, and goals related to home and family. For example, when Ryan was asked how he was able to be involved in various CR activities, this was one of his responses:

I guess I've become more oriented towards developing realistic, smart goals then following through. So I guess that's probably something I've done in the last 5 or 6 years. (Ryan [moderate CR cluster])

Personal factors as barriers. Personal factors also presented as barriers to CR. Participants who described aspects of low self-efficacy, had unsuccessful efforts or no efforts to overcome barriers, were not motivated to reintegrate, and had vague to no goals related to their CR struggled with CR. Some participants described their ongoing and disabling struggle with getting past their often self-imposed personal barriers.

I'm not as active as I would like to be. . . So that one would be something I wish I would do more, but at this point in my life, I'm not really down to put the energy into it. (Jack [moderate CR cluster])

Vague goal-setting without a clear plan of achieving the goals seemed to contribute to poor CR. Some participants expressed only one or two goals that tended to address broad aspects of their lives, such as being happier and making more money. Meanwhile, other participants had no goals related to $\mathrm{CR}$ or otherwise. When asked whether they had any goals for $\mathrm{CR}$, common responses resembled Sarah's response:

(Goals are) not really set in stone, by this date or this time frame kind of goal, but I would like to go back to school to do something different. ... I'd like to find something that motivates me, or helps me get passionate about life again. You know, just be able to have more happy days than sad days. (Sarah [low CR cluster])

\section{Adapted Sports, Recreation, and Other Social Programs} (Indirect Influence)

Adapted sports, recreation, and other social programs were discussed very frequently and with high regard as facilitators of CR. These programs were examples of participation in community activities, yet these events and programs served a larger purpose than mere participation. Programs were the vehicle for CR through which development of social supports, self-efficacy, and other personal factors were gained. They helped establish connections with other people (e.g., other servicemembers, injured civilians) and provided participants with opportunities to push personal boundaries and realize their own potential. Participants who discussed frequent participation in these events discussed these psychosocial benefits. Specific to adapted sports, some participants described participation as highly influential to CR.

Because of the adapted sports I have been doing ... I go out and there are crowds and to do sports you have to go out and see crowds and see people and you have to interact. I think adapted sports has a lot to do with why I am so much better than what I was. (Samuel [high CR cluster])

So the first thing that I learned about being in a wheelchair was wheelchair rugby ... and once they got me out on the court and ya know, I could still see that we could have fun in chairs, and I think my real beginning of what I do today, ya know, I try to stay active. (David [high CR cluster]) 
Other recreation and social programs were also helpful with creating social connections and social supports that were critical to CR. Social programs consisted of organized events for servicemembers, including going to baseball games together, sharing meals together, completing $5 \mathrm{k}$ races, and others.

Social activities, meaning going to a baseball game, having cookouts, or it can be doing $5 \mathrm{k}$ runs, or yoga groups, stuff like that. They've been very instrumental for me, and some other people as well, to help in that process because you can go there and identify with so many people. ... It helps, gives you that feeling that you had when you were in (the military), to be a part of something. (Kathy [moderate CR cluster])

For some participants, adapted sports, recreation, and social programs acted as a facilitator of CR as well as the only community activities in which they participated.

I did rowing, snowboarding, shooting, biking, there's a lot of sports, even some scuba diving. ... Right now, I only attend rehab. It's the only thing, rehab and the rec(reation) activities for veterans. For now, that's it. (Anthony [low CR cluster])

\section{Rehabilitation Programs and Therapists (Indirect Influence)}

As participants described their rehabilitation experiences, the quality and type of rehabilitation programs attended made a difference in preparing them for CR.

Rehabilitation programs and therapists as facilitators. Some participants identified their rehabilitation program as the initial facilitator of CR that taught them how to overcome barriers through the use of CR-promoting interventions and activities such as adaptive sports and community outings. Continued participation in these activities led to increased social support and increased self-efficacy and other personal factors that facilitated their ongoing CR.

When I left the military rehab, I could touch my thumb to my pinky and that was it, and they said, "That's your new life, get used to it." When I was going through civilian rehab, they kept pushing me and they said, "No, don't accept limitations. Keep going and push yourself," and they introduced me to the sports side of wheelchair life.... By doing the sports, I met other disabled veterans $\ldots$ and that pushed me out there into a whole new world and you realize that there is more to life than just sitting in your house in a chair. (Samuel [high CR cluster])

Peer mentors during the rehabilitation program who were injured servicemembers also assisted with supporting participants. Having mentors early in the rehabilitation process was very influential in beginning the process of CR. Serving as a mentor and helping support other injured servicemembers was a common activity of participants as well.

I think going back to my rehab process is, what led me to those activities (various volunteering activities), is that I had a great set of peer mentors, if you will, that were amputees from other wars from Vietnam, Korea, things like that, who were there, they supported me . . . they got me involved in the stuff. Sort of, really ingrained in my mind, should you get the second chance, you better make the most of it. (Ryan [moderate CR cluster])

The relationships established with the therapists within the rehabilitation programs served as facilitators of CR during rehabilitation and after discharge from rehabilitation. Therapists made connections with the participants by balancing the therapist and friend roles. For many participants, therapists were the catalysts to introduce them to adapted sports and other CR experiences.

Actually I found out (about opportunities for adapted sports) from my therapist from Augusta at the VA. ... They told me about the Winter Sports Clinic which started out in Aspen and once I got addicted and hooked on skiing, uh, my name was dropped into, I think, Breckenridge is where I learned how to ski. (David [high CR cluster])

In addition, vocational rehabilitation was commonly mentioned as a facilitator to going back to school or finding a job. Participants discussed how vocational rehabilitation services provided through the VA helped with finding jobs and funding their education.

Primarily (what) helped was, I did the voc rehab and I mean I thought I would go back to school and paid for it myself but obviously the money from the VA was, you know, spectacular. . . I I was really glad for the voc rehab because that's, you know, grad school down there was really expensive. (Ethan [high CR cluster])

Rehabilitation programs and therapists as barriers. Insufficient rehabilitation and medical programs and 
personnel also presented as barriers to CR. Participants noted their inability to reintegrate successfully after they attended rehabilitation and medical programs that focused on treating injuries alone, neglected to assist them with making the $\mathrm{CR}$ process a lifestyle change, or did not understand how to treat mental health issues in addition to physical injuries.

The rehabilitation I received while I was at the VA, they just wanted to slap a Band-Aid and get me out the door. They were not really interested in recovery or long-term care, they just wanted to get me stable and gone. That's all they seemed to care about. ... The civilian care was much better. They were much more concerned about my long term healthcare and getting me an actual lifestyle adjustment. (Samuel [high CR cluster])

\section{School, Work, and Volunteering (Indirect Influence)}

Supportive school, work, and volunteer environments were also instrumental to CR. Participants described the ways that employers and coworkers acted as supports and hindrances to their ability to maintain employment as part of their CR.

School, work, and volunteering as facilitators. Involvement in supportive school, work, and volunteer environments assisted with development of social supports, created the opportunity to provide support to others, and assisted with being a part of the community. Employers and coworkers who attempted to understand the participants' injuries, made accommodations, and provided emotional support facilitated participants' ability to maintain employment and develop supportive relationships.

I guess what helped me (with reintegration) was just meeting new people and going out to activities with new friends that I made at school, and trying to get involved in some of those activities. (Nick [high CR cluster])

School, work, and volunteering as barriers. Participants recognized that lack of social support at work, employer's lack of knowledge about mental health issues, and mental health stigma at work were barriers to job performance, maintaining a job, and creating social connections.

We go through all the training and suicide awareness and prevention and all that stuff, but I tell you what, there's nobody in my work environment that knew me really well that ever saw any signs or ever knew. So, that process for me felt a little isolated or alone because you don't want to say anything, you don't want to go to your boss and go, "I think I'm depressed. I'm having these thoughts." You know? It's a tough process to do. (Kathy [moderate CR cluster])

\section{Organizations and Policies (Indirect Influence)}

In many ways, government-funded and nongovernment-funded organizations and policies influenced CR by providing the means that enabled programs, services, and resources offered. All participants mentioned or discussed at least one organization that either facilitated or hindered the CR process. These organizations provided one or more of the following programs and services: (1) primary care services; (2) rehabilitation programs and individual therapy services; (3) mental health services; (4) adapted sport, recreation, and social programs; (5) tuition assistance programs; (6) job placement services; (7) case management services; (8) therapy dog placement programs; (9) prosthetic services; and (10) accessibility services. Meanwhile, other participants discussed the absence of organizations or policies as a barrier to CR. A policy analysis was not conducted in the study to verify accuracy of participant reflections on organization and policies; therefore, this theme was a result of participant narratives.

Organizations and policies as facilitators. The most commonly discussed government-funded organizations were the VA, Walter Reed National Military Medical Center, and the Wounded Warrior programs affiliated with a single branch of the military (e.g., Navy Wounded Warrior, Special Operations Command Care Coalition). These organizations offered many programs, services, and policies that facilitated CR. Participants also stressed the importance of policies and programs, such as pension and disability benefits, policies that support funding for adaptive recreation equipment, the GI Bill, and Continuation of Active Duty/Continuation of Active Reserve in their efforts to reintegrate. Other policies that benefit civilians also assisted, such as the Family and Medical Leave Act and the Americans with Disabilities Act.

Care providers get paid now to take care of their spouses. ... My wife went from unpaid laborer to being paid to take care of me. ... This has been a huge help for us. (Samuel [high CR cluster])

I think policy in the VA as far as buying adaptive equipment has been beneficial to me. I have a 
basketball wheelchair. I have a hand cycle. (Ryan [moderate CR cluster])

Many nongovernment-funded organizations whose mission is to support injured and noninjured servicemembers were catalysts to $\mathrm{CR}$ by providing a number of adapted sports, recreation, and other social services and programs that facilitated CR by helping build social support and personal factors. Some of these organizations included the Wounded Warrior Project; Team Red, White, and Blue; Disabled Sports USA; Eastern Sierra Disabled Sports; the Law Enforcement Foundation; and the Alethia Foundation.

Eastern Sierra Disabled Sports . . it's more of a reintegration into sports, just showing injured people what they still can do. (David [high CR cluster])

The Wounded Warrior Project really helps with getting you back into the community. (Jacob [low CR cluster])

Team Red, White, and Blue . . . they're a nonprofit organization that helps us veterans with reintegration into the community through social activities and sporting activities. ... Sometimes you want to withdraw or stay at home and that's the good part of Team Red, White, and Blue. Okay there's stuff going on, the email's there, it's there, there's nothing you have to do but just show up. (Kathy [moderate CR cluster])

Organizations and policy as barriers. One of the most commonly reported barriers to CR was related to accessing Federal programs and services. Receiving retirement and disability payments were also a commonly reported barrier. Other barriers related to the overwhelmed VA system in processing referrals and requests for services. Because of the VA barriers to services, participants discussed seeking out other civilian services for assistance. Policies of government-funded organizations and gaps in policy also had an influence on CR. Barriers included insufficient policies to provide support for family members and no policy on receiving retirement pay in a timely manner, which limited participants' ability to participate in reintegration activities.

I'll have to say after you retire and you're waiting for your paycheck. That kinda hinders you because you can't do a whole lot when you don't have any money! . . . So that would be my biggest hindrance. (Kathy [moderate CR cluster])
Yeah, you know, it has been 10 years and I still don't have a housing grant so my house still isn't wheelchair adaptable, accessible. (Samuel [high CR cluster])

I think that one of the policies and things that are lacking is support for the children. So, you know, reintegration, when I came home and I lost my leg, my son was 5 years old, which is a lot for a 5 year old kid to take in. There was not policy for counseling for him, for counseling for us. (Ryan [moderate CR cluster])

\section{Group-Level Comparisons}

Although the previous themes were noticed in all CR clusters to some degree, there were differences among clusters regarding the influence of contextual factors. The following summaries explain the most notable differences between clusters of participants based on CR scores.

\section{High Community Reintegration Cluster}

Participants from the high CR cluster described being very active in many more home and community activities, including family activities, adapted sport and recreation, and social activities with other servicemembers and civilians. This cluster had mostly positive rehabilitation experiences that prepared participants for $\mathrm{CR}$ through either military-specific rehabilitation programs or nonmilitary-specific programs. Overall, they reported many facilitators of reintegration and very few barriers. They acknowledged the existence of potential contextual barriers, but in nearly every situation, they described how they overcame the barriers or found ways around the barriers. It was apparent that participants in the high $\mathrm{CR}$ cluster had strong social support systems in regards to family, friend supports, and support from other injured servicemembers. Participants also described how their personal beliefs about themselves helped them with CR. Motivation to reintegrate was also a factor that set them apart from participants in other clusters.

\section{Moderate Community Reintegration Cluster}

The participants from the moderate CR cluster reported being active in their homes and communities, but they also recognized they could be more active and reintegrated. The moderate CR cluster reflected qualities of both the high and low reintegration clusters. Similar to the high reintegration cluster, the moderate CR cluster reported many facilitators of reintegration, such as social 
supports, personal factors, and participation in veteran support organizations. However, they were also similar to the low CR cluster because they described being hindered by various contextual factors such as (1) financial barriers, (2) VA backlog issues, (3) negative attitudes and support from other people, (4) poor self-efficacy and motivation at times, and (5) hindrances because of psychological injuries. It was also notable that two of the three participants discussed thoughts of suicide at one point in their lives. No other groups mentioned suicide during interviews.

\section{Low Community Reintegration Cluster}

Participants in the low CR cluster had very different rehabilitation experiences than the high $\mathrm{CR}$ cluster. The participants who received VA services were not satisfied with the treatment they were provided, which caused them to seek non-VA or small local VA rehabilitation programs. These programs were perceived as being ill-prepared to treat the complex injuries associated with servicemembers. Therefore, participants in the low CR cluster were not well prepared for CR after rehabilitation. Opposite to the high CR cluster, the participants in the low CR cluster reported many more barriers than facilitators. Barriers tended to include problems with (1) personal factors (e.g., low selfefficacy, lack of motivation, poor self-view, inadequate goal setting); (2) the VA system and other rehabilitation services; (3) attitudes, support, and stigma from other servicemembers, civilians, and coworkers; (4) psychological injuries; and (5) problems with obtaining relevant information about $\mathrm{CR}$ resources. However, facilitators to $\mathrm{CR}$ were discussed, such as receiving services and assistance from veteran support organizations and social support from family and other servicemembers. It should be noted, however, that two of the three participants were less than $3 \mathrm{yr}$ postinjury, which may have been inadequate time to fully reintegrate.

\section{DISCUSSION}

This qualitative study captured the subjective experiences of community-dwelling, injured servicemembers in regards to how contextual factors facilitated or hindered their CR. Thematic analysis indicated social support and personal factors (e.g., self-efficacy, personal motivation) were the primary influences on CR. Other themes included the important roles of adapted sports, recreation, and other social programs; rehabilitation programs and therapists; school, work, and volunteering; and organizations and policies in developing social supports and selfefficacy and, therefore, influencing CR. When the themes were compared between CR clusters, participants in the low CR cluster reported many more contextual barriers and far fewer contextual facilitators to CR than the high $\mathrm{CR}$ cluster. The moderate CR cluster was unique in that they reported many facilitators to CR but also reported many barriers as well.

This study supports the literature on the effect of environmental factors, especially the role of social support among injured servicemembers. Social support from family, friends, and other servicemembers played an integral role in CR of injured servicemembers, similar to findings of previous studies regarding the connection between social support and quality of life [30], social support and suicide prevention [13], and preference toward mental health services utilizing family-based interventions [14]. The results of this study also support the social benefits and sense of camaraderie associated with participation in adapted sports and recreation among injured servicemembers [15-16]. In agreement with previous literature, this study provides merit to the use of therapeutic modalities that employ a holistic focus to assist injured servicemembers with CR as well as other outcomes associated with rehabilitation and recovery [31-32].

Findings from this study, in addition the previous literature on CR $[1,4,7,33]$, support that CR is a much more complex process than the injured servicemember's ability to adjust to his or her injuries and impairments. Instead, CR is largely dependent on the injured servicemember's ability to manipulate his or her own intrapersonal context, interpersonal interactions, and interenvironmental interactions. The injured servicemember's ability to adjust to and utilize those internal and external environments seemed to heavily influence his or her success with CR. For example, participants who were proficient at self-regulating (e.g., being motivated and finding motivation, overcoming challenges, and negotiating barriers), seeking and establishing critical social supports, and maximizing their social and physical environments were more likely to reintegrate with greater success than those who were less proficient at one or more of these skills. While some of these skills are inherent to the individuals and their particular background, other skills can be learned and practiced, which explains the reported benefits of participation in rehabilitation, adapted sports and recreation, and other support programs within this study. However, the barriers faced with accessing necessary med- 
ical services through the VA, for example, and gaps in governmental policies affected participants from all CR clusters.

\section{Implications for Practice}

Many implications for rehabilitation practice can be drawn from this study. Rehabilitation programs have the potential to be the first facilitators of CR for injured servicemembers. Many participants in this study discussed how physical and mental health rehabilitation programs helped them recover from injury while also teaching them how to make a lifestyle change that supports active living. Rehabilitation programs that followed a holistic and ecological approach to treatment, not merely treating their injuries, were perceived to have a greater effect on their CR. Providing opportunities for injured servicemembers to practice $\mathrm{CR}$, such as community outings and adapted sports programs, were the first steps toward creating socially and physically active lifestyles after injury. Likewise, participants who received rehabilitation programs that did not focus on a lifestyle change and did not adequately consider their psychological injuries, in addition to their physical injuries, struggled with CR.

Rehabilitation programs should consider implementing services that address the contextual influences to CR, with particular focus on providing opportunities to increase self-efficacy and increase social supports. Properly educating and training family members on the injuries of their servicemember and how they can help them with CR could be beneficial. Programs designed to address and improve family functioning prior to discharge may also assist both the servicemembers and their families with the transition home.

Many participants reported the benefits of having peer mentors who were injured servicemembers and getting involved with adapted sports and other social programs during rehabilitation. These programs increased participants' social support system and assisted their sense of accomplishment and realization of their own potential. Therefore, rehabilitation programs will benefit from establishing peer mentoring programs, sport and recreation opportunities, and social programs. Although some military medical and transitional centers and civilian rehabilitation programs offer these types of services, many do not. As the data suggest, participants who attended rehabilitation programs that did not provide these services had a more difficult experience with $\mathrm{CR}$ and were not adequately prepared to return to active participation in their home and community. Professionals, such as recreational therapists, who specialize in these types of services are best suited to develop and implement these programs.

Collaborations with organizations that support injured and noninjured servicemembers may be instrumental in providing these programs as well. These organizations may include adapted sports organizations such as Paralympic sport clubs, the Wounded Warrior Project, and other wounded warrior support programs. Making connections with these community resources during rehabilitation will further assist the transition to their home and community.

\section{Future Research}

The need for additional research on CR remains. Although not the original intention of the study, the structure of the contextual factors resembles a path model for CR. These qualitative results pose the question of whether the structure would uphold to quantitative analyses such as structural equation modeling. Further studies could measure and test these relationships. Since this study reported how contextual factors affect CR, programs with a socioenvironmental focus should be developed and evaluated to further understand how to assist injured servicemembers with their CR. Since many rehabilitation, transitional, and community-based programs are already in place, additional studies could focus on evaluating existing programs to determine the extent to which they are assisting injured servicemembers with CR. Similar to this study, mixed methodologies may be the best means to capture the overall effectiveness of these programs [1].

\section{Limitations}

One limitation of this study was the between-cluster comparisons since only three participants were interviewed within each cluster. The three individuals may not be adequate to draw conclusions representative of all participants within their respective cluster. The comparisons represent this sample only, and more research is necessary to determine whether they are generalizable to a larger group. Additional limitations may be due to the sampling procedures. For example, the manner in which the participants were recruited may have contributed to an overrepresentation of participants who were active in adapted sports and recreation programs since many Paralympic and other adapted sports programs were contacted for participant recruitment. 


\section{CONCLUSIONS}

Understanding the experience of CR from the injured servicemember's perspective added to the clarity of how contextual factors influence CR. This study demonstrated the critical role that personal factors and social support play in the process of adjusting to home and community participation, as well as the contributors to the development of personal factors and social support. Rehabilitation programs should evaluate the manner in which they are providing opportunities to assist injured servicemembers with building skills to negotiate barriers to CR and locate resources that will facilitate CR in the months and years following rehabilitation.

\section{ACKNOWLEDGMENTS}

\author{
Author Contributions: \\ Study concept and design: B. L. Hawkins, F. A. McGuire, \\ S. M. Linder, T. W. Britt. \\ Acquisition of data: B. L. Hawkins. \\ Analysis and interpretation of data: B. L. Hawkins, F. A. McGuire. \\ Drafting of manuscript: B. L. Hawkins, F. A. McGuire, S. M. Linder, \\ T. W. Britt. \\ Administrative, technical, or material support: S. M. Linder, \\ T. W. Britt.
}

Financial Disclosures: The authors have declared that no competing interests exist.

Funding/Support: This material was unfunded at the time of manuscript preparation.

Additional Contributions: The authors would like to thank the organizations and individuals who assisted in recruitment of participants.

Institutional Review: Institutional Review Board approval was obtained at Clemson University (IRB2012-213).

Participant Follow-Up: The authors have no plans to notify the study subjects of the publication of this article because of a lack of contact information.

\section{REFERENCES}

1. Crocker T, Powell-Cope G, Brown LM, Besterman-Dahan $\mathrm{K}$. Toward a veteran-centric view on community (re)integration. J Rehabil Res Dev. 2014;51(3):xi-xvii. [PMID:25019672] http://dx.doi.org/10.1682/JRRD.2014.01.0011

2. Minnes P, Carlson P, McColl MA, Nolte ML, Johnston J, Buell K. Community integration: A useful construct, but what does it really mean? Brain Inj. 2003;17(2):149-59.

[PMID:12519641] http://dx.doi.org/10.1080/02699050301828
3. Resnik L, Gray M, Borgia M. Measurement of community reintegration in sample of severely wounded servicemembers. J Rehabil Res Dev. 2011;48(2):89-102. [PMID:21480084] http://dx.doi.org/10.1682/JRRD.2010.04.0070

4. Resnik LJ, Allen SM. Using International Classification of Functioning, Disability and Health to understand challenges in community reintegration of injured veterans. J Rehabil Res Dev. 2007;44(7):991-1006. [PMID:18075956] http://dx.doi.org/10.1682/JRRD.2007.05.0071

5. Resnik L, Plow MA. Measuring participation as defined by the International Classification of Functioning, Disability and Health: An evaluation of existing measures. Arch Phys Med Rehabil. 2009;90(5):856-66. [PMID:19406308] http://dx.doi.org/10.1016/j.apmr.2008.11.010

6. Resnik L, Plow M, Jette A. Development of CRIS: Measure of community reintegration of injured service members. J Rehabil Res Dev. 2009;46(4):469-80. [PMID:19882482] http://dx.doi.org/10.1682/JRRD.2008.07.0082

7. Resnik L, Bradford DW, Glynn SM, Jette AM, Johnson Hernandez C, Wills S. Issues in defining and measuring veteran community reintegration: Proceedings of the Working Group on Community Reintegration, VA Rehabilitation Outcomes Conference, Miami, Florida. J Rehabil Res Dev. 2012;49(1):87-100. [PMID:22492341] http://dx.doi.org/10.1682/JRRD.2010.06.0107

8. Whiteneck G, Meade MA, Dijkers M, Tate DG, Bushnik T, Forchheimer MB. Environmental factors and their role in participation and life satisfaction after spinal cord injury. Arch Phys Med Rehabil. 2004;85(11):1793-1803. [PMID:15520974] http://dx.doi.org/10.1016/j.apmr.2004.04.024

9. Lysack C, Komanecky M, Kabel A, Cross K, Neufeld S. Environmental factors and their role in community integration after spinal cord injury. Can J Occup Ther. 2007;74(5 Suppl):243-54. [PMID:17844979] http://dx.doi.org/10.1177/000841740707405S03

10. Wang PP, Badley EM, Gignac M. Exploring the role of contextual factors in disability models. Disabil Rehabil. 2006;28(2):135-40. [PMID:16393844] http://dx.doi.org/10.1080/09638280500167761

11. Noreau L, Boschen K. Intersection of participation and environmental factors: a complex interactive process. Arch Phys Med Rehabil. 2010;91(9 Suppl):S44-53. [PMID:20801279] http://dx.doi.org/10.1016/j.apmr.2009.10.037

12. World Health Organization. The International Classification of Functioning, Disability and Health. Geneva (Switzerland): World Health Organization; 2001.

13. Bryan CJ, Kanzler KE, Durham TL, West CL, Greene E. Challenges and considerations for managing suicide risk in combat zones. Mil Med. 2010;175(10):713-18. 


\section{[PMID:20968259]}

http://dx.doi.org/10.7205/MILMED-D-09-00248

14. Khaylis A, Polusny MA, Erbes CR, Gewirtz A, Rath M. Posttraumatic stress, family adjustment, and treatment preferences among National Guard soldiers deployed to OEF/OIF. Mil Med. 2011;176(2):126-31. [PMID:21366071] http://dx.doi.org/10.7205/MILMED-D-10-00094

15. Hawkins BL, Cory LA, Crowe BM. Effects of participation in a paralympic military sports camp on injured service members: Implications for therapeutic recreation. Ther Recreation J. 2011;45(4):309-25.

16. Mowatt R, Bennett J. War narratives: Veteran stories, PTSD effects, and therapeutic fly-fishing. Ther Recreation J. 2011;45(4):286-308.

17. Wands L. "No one gets through it OK": The health challenge of coming home from war. ANS Adv Nurs Sci. 2013; 36(3):186-99. [PMID:23907301] http://dx.doi.org/10.1097/ANS.0b013e31829edcbe

18. Creswell JW, Plano Clark VL. Designing and conducting mixed methods research. Thousand Oaks (CA): Sage Publications; 2011.

19. Redding CA, Rossi JS, Rossi SR, Velicer WF, Prochaska JO. Health behavior models. Int J Health Educ. 2000; 3(3):180-93.

20. Hawkins BL, McGuire FA, Britt TW, Linder SM. Identifying the contextual influences of community reintegration among injured servicemembers. J Rehabil Res Dev. 2015; 52(2):235-46.

21. Creswell JW. Qualitative inquiry and research design: Choosing among five traditions. 3rd ed. Thousand Oaks (CA): Sage Publications; 2012.

22. Onwuegbuzie AJ, Collins KM. A typology of mixed methods sampling designs in social science research. Qual Rep. 2007;12(2):281-316.

23. Sturges JE, Hanrahan KJ. Comparing telephone and faceto-face qualitative interviewing: A research note. Qual Res. 2004;4(1):107-18. http://dx.doi.org/10.1177/1468794104041110

24. Merriam SB. Qualitative research: A guide to design and implementation. San Francisco (CA): Jossey-Bass; 2009.

25. Long T, Johnson M. Rigour, reliability and validity in qualitative research. Clin Eff Nurs. 2000;4(1):30-37. http://dx.doi.org/10.1054/cein.2000.0106

26. Moustakas C. Phenomenological research methods. Thousand Oaks (CA): Sage Publications; 1994.

27. Cook KE. Reliability assessments in qualitative health promotion research. Health Promot Int. 2012;27(1):90-101.

\section{[PMID:21558285]}

http://dx.doi.org/10.1093/heapro/dar027

28. Maxwell JA. Qualitative research design: An interactive approach. 3rd ed. Thousand Oaks (CA): Sage Publications; 2013.

29. Lincoln YS, Guba EG. Naturalistic inquiry. Beverly Hills (CA): Sage Publications; 1985.

30. Yazicioğlu K, Duyan V, Karataş K, Ozgü A, Yilmaz B, Duyan GC, Aksu S. Effects of sociodemographic characteristics, illness process, and social support on the levels of perceived quality of life in veterans. Mil Med. 2006; 171(11):1083-88. [PMID:17153546]

31. Uomoto JM, Williams RM. Post-acute polytrauma rehabilitation and integrated care of returning veterans: Toward a holistic approach. Rehabil Psychol. 2009;54(3):259-69.

[PMID: 19702424]

http://dx.doi.org/10.1037/a0016907

32. Pasquina PF, Tsao JW, Collins DM, Chan BL, Karmarkar AM, Cooper RA. Quality of medical care provided to service members with combat-related limb amputations: Report of patient satisfaction. J Rehabil Res Dev. 2008;45(7):953-60. [PMID:19165685]

http://dx.doi.org/10.1682/JRRD.2007.10.0163

33. Whiteneck G, Tate D, Charlifue S. Predicting community reintegration after spinal cord injury from demographic and injury characteristics. Arch Phys Med Rehabil. 1999; 80(11):1485-91. [PMID:10569445] http://dx.doi.org/10.1016/S0003-9993(99)90262-9

Submitted for publication August 25, 2014. Accepted in revised form April 7, 2015.

This article and any supplementary material should be cited as follows:

Hawkins BL, McGuire FA, Linder SM, Britt TW. Understanding contextual influences of community reintegration among injured servicemembers. J Rehabil Res Dev. 2015;52(5):527-42.

http://dx.doi.org/10.1682/JRRD.2014.08.0196

ResearcherID: Brent L. Hawkins, PhD, LRT/CTRS: J6998-2014

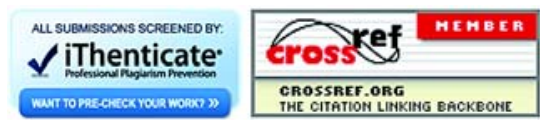


